\title{
THE LEARNING LAB DIRECTOR AS PUBLIC RELATIONS PERSON
}

\section{Bennett Cole}

So zealously do many Learning Lab Directors pursue the task of servicing the daily operational needs of the Lab and the department(s) it serves, that they seldom pause to reflect upon the role of the Lab vis-a-vis the ever-changing needs of the academic profession. This often results in a failure to perceive emerging areas of possible service and to react accordingly. One real but easily overlooked service function is that of public relations.

Operant in today's academic and economic milieu are diverse factors, well known to the foreign language teaching profession and often recited in its literature, that have produced a state in which foreign language study has paled considerably in attractiveness for the student, and in which foreign language departments find their image proportionately diminished. The Learning Lab Director, however, is in an admirable position to vigorously assert the value of foreign language study, make significant contributions to the department's curriculum, and enhance the department's general image. As Arthur Gionet (1975) has said, the responsibility for the image of the foreign language department is shared with the administration and the faculty, but "the language lab director could very well take the lead in this direction." In the discussion that follows I wish to simply ask a few questions and suggest some courses of action that may aid in the development of a more positive departmental image. Some of the suggestions will be totally irrelevant for certain institutions and others will be received as so contrary to established policy that they will be considered just plain laughable; some will be obvious and already tried while others may have been completely overlooked.

The Learning Laboratory's image has a quadruple projection: to the student, to the department, to the academic community as a whole, and to the local community. The suggestions are, herefore, accordingly grouped.

\section{Student}

For many students the Lab is their only contact with the foreign language department other than their classroom insructor. For the student, there is a real sense in which his instructor and the Lab equal the foreign language department. His lab experience figures prominently in his opinion of the foreign language department, its faculty, and foreign language learning in general. 
Is the ambience of your Lab conducive to foreign language leaming? Does your Lab exude the sterility of a surgical operating suite or does it have a "homey" look? Within your budgetary constraints, aim for a basic decor that is aesthetically pleasing. If your Lab is used mainly by foreign language students, as most Labs are, use decorations, posters, etc., that will subtly conjure up notions of things foreign, but avoid the secondrate travel agency look.

Do your Lab's hours of operation provide access to students during prime evening study time? Consider keeping the Lab open during evening hours. At V.P.I. \& S.U. we have found Sunday evenings to be surprisingly well attended. Saturday mornings have been successful at some institutions. Use every available means, however, to publicize the added hours.

Is your software boring and/or nonproductive? A periodic consultation with instructors on a regular basis about the programs they are using is beneficial. The most electronically sophisticated lab in the world is only as good as its software. The material produced by textbook publishers is not necessarily pedagogically better and certainly not necessarily more suitable or appealing to the student than locally produced materials that are tailor-made to suit specific goals and purposes. If your programming relies entirely on commercially made tapes, the chances are good that there is substantial room for improvement in your programming. One way to measure student reaction is to make available a student lab program evaluation form about mid-way through the quarter or semester. Since students are understandably reluctant to communicate their honest opinions to their instructor, especially if they think he chose the material they are evaluating, the Lab Director may serve as an intermediary, summarizing student opinion and forwarding it to the instructor.

Does your Lab inventory include a supply of individualized selfinstructional foreign language programs? These may be programs in the basic as well as in the more "unusual" languages. There are two possibilities: (1) the "Language $X$ for Travellers and Tourists" type for use by students and faculty preparing to do study or research abroad, and (2) the more complete self-instructional package course equivalent to a regular course offering. The latter is of special interest because it opens up the possibility of a student taking a foreign language course or a limitedobjective "mini-course" (e.g., Medical Spanish, Travelling in France, etc.) for credit, at his own pace and with flexible scheduling, since the student can attend the Lab at his own convenience. The usual arrangement for this kind of course is for the entire course to be administered in the Lab, with the student meeting with an assigned faculty member for periodic consultations and examination. Administration approval for type (2) courses may be difficult to obtain, but it is possible to secure approval if the course proposal is "solid" enough. Such programs have, in fact, 
been in existence for some time. The Language Lab at the University of Idaho, for instance, offers several one credit pass-fail courses in different languages and subjects. Altman and Brod (1978) have indicated that, contrary to the popular claim that individualized programs have proven to be a fad, the results in many programs have been gratifying and there is mounting evidence to support real cognitive gain in these programs as compared with so-called 'traditional' language programs.' Before investing in type (1) or (2) programs, however, it is advisable to record all requests received for such programs for at least a year prior to purchase in order to more easily justify your purchase request. Finally, if you already have on hand or decide to adopt some individualized programs, make sure that you advertise their availability in the campus newspaper, faculty newsletter, or other appropriate campus periodicals.

Does your Lab function as a foreign language information center? In many institutions the Learning Lab is a highly frequented spot on campus. You may be missing a royal opportunity to provide useful, practical information of diverse kinds to your students. Bulletin boards can be advantageously used to advertise such obvious things as summer employment notices, study abroad information, student lab assistant openings for next quarter, semester, or year, foreign language departmental functions, new foreign language courses soon to be offered, and individualized self-instructional foreign language programs available. A centrally located bulletin board devoted specifically to foreign language career information is worthy of consideration. At V.P.I. \& S.U. we are finding that the Lab is an excellent place to promote foreign language careers for we have a fairly heavy student traffic (approximately 1,000 students per week at the start of classes in the fall). Our board is strategically located at the tape check-out window where students must pause on entering and leaving the Lab. Our effort is directed mostly at showing how the study of a foreign language can benefit the non-foreign language major in his career. We have a departmental foreign language career advisor who, upon request, gives the student a thorough consultation after the board initially gets his attention.

Daes your Lab provide tape copying service for its users? Many students prefer to do their lab assignments at their convenience using their own cassette players. If you do not have a high speed cassette copier already on hand in your Lab, consider investing in one. At V.P.I. \& S.U., we use Telex I and IV Copiers, which duplicate a C-60 cassette in about four minutes onto a blank provided by the student, making "service-whileyou-wait" possible. High speed multiple cassette duplicators and reel-tocassette duplicators are also available if you should need them. Be sure to instruct your lab assistants not to reproduce copyrighted tapes, however, unless you specifically notify them that a copyright waiver has been granted. 
A good department faculty-Lab staff relationship to be deliberately cultivated-it just doesn't develop of its own accord. Foreign language faculty can be divided into two groups: those who use the Lab and AV (audio-visual) equipment and those who don't. Many of the latter group are fearful of appearing ignorant of AV equipment in front of a class and thus avoid its use altogether, while some are simply not aware of what the Lab's AV facilities really are. Hughett (1976) is correct when he says that it is becoming apparent that the learning lab can never fully reach its potential without the active involvement of the whole faculty with the lab director and his associates. A certain amount of education is involved in closing this relational gap. The reader who is interested in some useful concrete guidelines for Lab-faculty relations should see Ciceran and Dahm's article on lab administration.

Do you hold periodic workshops for departmental faculty in the use of AV equipment? In addition to the more obvious skills of movie, slide, filmstrip, and overhead projection, to be imparted to faculty in workshop sessions, one might consider other activities such as tape duplication, the production of AV synchronized programs, and photography for the faculty member who wants to take his own slides for classroom use. For the latter, if the Lab Director or Technician is not a photographer, consider buying a camera for the Lab and providing training in photography for him. He, in turn; can pass his skills on to department faculty who express an interest in photography.

Do you maintain a continuing dialogue with faculty conceming software? The Lab Director needs to talk frequently with faculty teaching courses with a lab component in order to provide constant "on-going" evaluation of the software.

Do you serve as "clearing house" for new AV materials? You should, if that function is not directly assigned to someone else in your department. Get to know the faculty in all languages and the kinds of courses they typically teach so that you can spot new AV materials of potential interest to them and inform them.

Do you provide photographic-copying service for your department? This is a frequently overlooked possible area of service. If the Lab, Director or Technician has no expertise in this process, which the average amateur photographer can learn with a moderate expenditure of effort, arrange for some instruction. Your Lab will then be able to produce slides of textbook photos, diagrams, etc., for classroom use. If the cost of acquiring a good $35 \mathrm{~mm}$. camera is prohibitive or greatly out of proportion to the anticipated requests for this service, a personally owned or borrowed camera can be used. The procedure involved also calls for a close-up lens 
set and a camera stand with lights, all of which can be purchased for less than one hundred dollars if you shop around a bit. Send your exposed film to your institution's photo lab or a commercial firm.

Do you offer your services as a consultant on the use of Leaming Labs and AV equipment? Start a small library of texts on Learning Labs. Since information on Lab use is frequently found in mtthodology texts, your library could naturally extend itself into a methodology reference center for your department. If you have in your department or institution a foreign language methodologist or supervisor of student teachers in foreign languages, maintain close contact with that person. Offer to give lab tours to your methodologist's or supervisor's students and to conduct mini-workshops on the operation of AV equipment and on such topics as tape duplication, splicing, slide-sound synchronized program production, etc.

Does your Lab have a professional quality sound recording studio for faculty use? One of the chief drawbacks to the use of locally produced tapes is the poor quality that results from the use of portable equipment in the office or at home. Problems involving poor volume and tone control, background noise, extraneous sounds, off-on clicks, etc., are genuinely distracting. If you do not have a studio, mount a campaign to get one. We have recently completed one here at V.P.I. \& S.U. by converting some existing space in the Lab workshop-office area. The Lab Technician designed and supervised the construction, which was carried out by university carpenters, and the total cost was approximately two thousand dollars. Our studio, which contains two swivel boom mikes and accommodates up to three persons, has a window to the control area where the Lab Technician, using professional quality recording equipment, controls the whole operation. Result: a problem-free, efficient recording session for the faculty member and a high quality tape for the student to listen to.

\section{Academic Community.}

The key to establishing an effective relationship with the academic community outside of the department housing the Lab lies in a vigorous and consistent campaign to make the Lab and its services well known on campus, assuming that it is, in fact, desirable to make the Lab available for use by the academic community at large. This essentially means making the services known within your institution.

Do other departments or colleges within your institution know about the Lab? Prepare letters or flyers to send to department heads and college deans, inviting them to tour the Lab to see if their students could profit from use of the Lab. Let them know that you are not only able but also 
willing to store, duplicate, and make available for student use, tapes of any special lectures or lecture series that they may sponsor. After they initiate use of the Lab, maintain good liaison with them. At V.P.I. \& S.U., among the departments who send students to us, for example, are English (English as a Foreign Language and Remedial English), Music, Communications, and International Studies.

Have you forgotten that faculty members can be students too? Widely advertise the availability of your self-instructional foreign language programs. In a large university don't be surprised to get a good response, for there are frequently faculty preparing for research or travel abroad who want to acquire language " $X$," or a smattering of it, on their own rather than take the regular classroom course offering. Most colleges and universities have at least a few "closet language nuts" who are not in the foreign language department but who are interested in language study for its own sake. There are also those who for various reasons need an "unusual" language that is not offered as a course in your institution. This is an excellent way to build bridges with other departments, for the resulting relationship will be a personal, faculty member-to-Lab staff relationship.

\section{Local Community and Beyond}

Efforts in this area are contingent upon two factors: (1) the extent to which the Lab facilities can be made available to the public without running afoul of institutional rules and policies, and (2) the degree to which the Lab Director is self-motivated to represent his lab, department, and institution beyond the campus.

Do you make your resources available to neighboring institutions and individuals in the community? This, of course, may not accord with your institution's policies, so you must proceed with caution. Among the possibilities are lending software to neighboring institutions for instructional purposes and providing them with full tape duplication service. The question of whether or not it is feasible or permissible to open up the Lab for use by the general public is problematical but worth investigating. A proposal that is more likely to gain administrative approval is to develop complete, self-instructional course packages, for which the individual must formally register and pay tuition. These could then be made available to anyone in the academic or local community who properly registers for the course. The obvious advantage of this kind of offering is that it can provide maximum flexibility in the working student's choice of hours for Lab attendance.

Do you personally project the Lab beyond the campus? It goes without saying that you should take advantage of every opportunity to meet 
the public and your colleagues from other institutions. Attending professional conferences, reading papers, etc., are not only professionally beneficial activities but also may have a public relations aspect, since such activities have a way of making the local and campus newspapers. A project planned for the near future at V.P.I. \& S.U.'s Learning Lab is the preparation of a slide-tape synchronized program describing our Department of Foreign Languages and Literatures. This will include slides of our students engaged in various foreign language activities, in study abroad programs, etc. This will then be made available for use by local high school guidance counsellors, by our foreign language faculty giving talks at our local schools and other organizations, and made available to visiting high school students contemplating foreign language studies at V.P.I. \& S.U.

The reader who is interested in strengthening his Lab's external relations beyond the suggestions made here would do well to see the suggestions of Ciceran and Darhms (1978) in their article on guidelines for language laboratory administration.

\section{Summary}

The above list of questions is not exhaustive and what is perhaps more obvious is that it reflects the author's admittedly somewhat personal view of what constitutes an ideal Learning Lab siuation. I believe, however, that other Learning Lab Directors, will find my questions and suggestions sufficiently relevant to their own situation to encourage them to assess their own lab's role in enhancing the image of their department and profession.

\section{References}

'Arthur J. Gionet, "A Challenge to Language Learning Directors," NALLD Journal, Vol. IX, No. 3 (Spring 1975), p. 12.

2Howard B. Altman and Richard I. Brod, "College and University Foreign Language Programs-New Forms, New Emphases, New Content," Change (Report on Teaching No. 5), Vol. 10, No. 1 (January 1978), p. 29.

sHarvey Hughett, Jr., "Speeding Up the Learning Lab," Audio-Visual Communications, December 1976, p. 44.

4A. J. Ciceran and R. G. Dahms, "Language Laboratory Administration: A Checklist of Selected Guidelines," NALLD Journal, Vol. XII, Nos. 3,4 (Spring/Summer 1978), pp. 36-37.

slbid, p. 37.

Bennett Cole, Assistant Professor of Spanish, Department of Linguistics, Virginia Polytechnic Institute, Blocksburg, VA. 24061. 